\title{
PENGUKURAN LEVEL KETINGGIAN AIR MENGGUNAKAN FIBER BRAGG GRATING (FBG) BERBASIS MODULASI INTENSITAS LASER DIODA
}

\author{
Andi Setiono ${ }^{1, *}$, Ratna Yulia Sari ${ }^{2}$ \\ ${ }^{1}$ Pusat Penelitian Fisika LIPI \\ Kawasan PUSPIPTEK Serpong Gd. 442, Tangerang Selatan, Banten 15314 \\ ${ }^{2}$ Program Studi Fisika \\ Fakultas Sains dan Teknologi, Universitas Airlangga, Jl Mulyorejo No. 4-6 Surabaya 60115
}

${ }^{*}$ Email: andisetiono@gmail.com, andi.setiono@lipi.go.id

\begin{abstract}
Abstrak
Pada studi ini telah dilakukan penelitian tentang pengukuran level ketinggian air menggunakan Fiber Bragg Grating (FBG). Pengukuran ini dilakukan dengan cara meregangkan FBG menggunakan kantilever yang dikaitkan dengan pelampung. Peregangan menyebabkan perioda kisi-kisi FBG berubah dan selanjutnya mempengaruhi respon transmisi cahaya yang merambat didalamnya. Pada penelitian ini, level ketinggian air diukur dengan cara mendeteksi respon intensitas cahaya laser dioda yang ditransmisikan melalui FBG. Panjang gelombang laser dioda dan panjang gelombang Bragg FBG yang digunakan berturut-turut yaitu 1553,96 nm dan $1554 \mathrm{~nm}$. Hasil penelitian menunjukkan bahwa terdapat hubungan linier antara respon intensitas cahaya laser dioda dengan level ketinggian air. Sensitivitas dan resolusi pengukuran berturut-turut $0,69 \mathrm{dbm} / \mathrm{mm}$ dan $1 \mathrm{~mm}$.
\end{abstract}

Kata-kata kunci: Fiber bragg grating, sensor level ketinggian air, modulasi intensitas laser dioda.

\begin{abstract}
Measurement of water level use Fiber Bragg Grating (FBG) was studied. The measurement was done by straining FBG use cantilever which connected to the cork. By straining of the FBG, grating period will have changed and further affect the transmission response of the propagated light. In this study, the water levels were measured by detect intensity of transmitted laser diode. Wavelength of laser diode and FBG Bragg wavelength were $1553.96 \mathrm{~nm}$ and $1554 \mathrm{~nm}$, respectively. The results showed that there is a linear relationship between intensity of transmitted laser diode with the water levels. Sensitivity and resolution were $0.69 \mathrm{dBm} / \mathrm{mm}$ and $1 \mathrm{~mm}$, respectively.
\end{abstract}

Keywords: Fiber bragg grating, water level sensor, modulation of laser diode intensity.

\section{Pendahuluan}

Monitoring level ketinggian air sangat diperlukan dalam beberapa aspek kehidupan manusia. Sebagai contoh, monitoring level air pada suatu waduk sangat diperlukan sebagai langkah antisipasi bencana banjir. Selain itu, pemantauan level ketinggian air juga diperlukan dalam bidang industri dan rumah tangga, seperti monitoring level air pada suatu tangki penampung. Pengukuran level ketinggian air telah banyak dikembangkan dengan berbagai metode antara lain metode mekanis, elektronik, ultrasonik, dan optik [1]. Metode optik dinilai lebih tahan terhadap lingkungan yang bersifat konduktif dan eksplosif dibanding metode yang lain. Selain itu, metode optik juga tahan terhadap gangguan interferensi gelombang magnetik. Beberapa sensor level ketinggian cairan berbasis fiber optik telah dikembangkan beberapa tahun terakhir [2]. Perkembangan terakhir, beberapa sensor level berbasis Fiber Bragg Grating (FBG) juga telah dikembangkan, antara lain menggunakan long period grating, etched fiber Bragg grating [3], dan side-polished fiber Bragg grating [4]. Prinsip kerja pada sensor FBG tersebut lebih banyak pada pengukuran perubahan panjang gelombang Bragg/ Bragg resonance. 
Pada penelitian ini, pengukuran level ketinggian air dilakukan dengan cara mengukur respon transmisi intensitas laser dioda dalam FBG yang diregangkan oleh kantilever. Perubahan intensitas laser dioda memiliki hubungan yang linier terhadap perubahan level ketinggian air.

\section{Metode Penelitian}

Fiber Bragg Grating (FBG) adalah serat optik yang memiliki kisi-kisi yang tersusun secara periodik. Kisikisi tersebut merupakan variasi indeks bias di dalam inti serat [5]. Dengan adanya variasi indeks bias yang seragam, FBG dapat memantulkan panjang gelombang yang bersifat unik, disebut sebagai panjang gelombang Bragg. Panjang gelombang Bragg ( $\left.\lambda_{\text {Bragg }}\right)$ diformulasikan dengan Persamaan 1.

$$
\lambda_{\text {Bragg }}=2 n_{\text {eff }} \Lambda
$$

dimana $\mathrm{n}_{\text {eff }}$ adalah indeks bias efektif dari inti serat optik; $\Lambda$ adalah periode kisi-kisi FBG.

Panjang gelombang Bragg suatu FBG dapat diketahui dengan merambatkan sumber cahaya broadband kedalam FBG, seperti ditunjukkan pada Gambar 1. Cahaya dengan panjang gelombang yang berbeda dengan kondisi Bragg akan diteruskan oleh kisi-kisi FBG. Sebaliknya panjang gelombang yang sesuai dengan kondisi Bragg akan dipantulkan oleh kisi-kisi FBG. Pada kondisi nyata, FBG tidak mutlak hanya memantulkan satu cahaya yang sama persis dengan kondisi Bragg, tetapi juga memantulkan cahaya lain. Cahaya-cahaya ini memiliki panjang gelombang yang sangat dekat dengan panjang gelombang Bragg dan dipantulkan dengan intensitas lebih kecil. Cakupan pemantulan panjang gelombang ini tergantung dari spesifikasi bandwidth FBG yang selanjutnya dipengaruhi oleh jumlah kisi-kisi didalamnya. Berdasarkan kondisi ini maka dapat diketahui bahwa jarak antar kisi FBG mempengaruhi tingkat transmisifitas FBG terhadap panjang gelombang yang sangat dekat dengan panjang gelombang Bragg FBG. Kondisi ini selanjutnya dimanfaatkan untuk mengembangkan sensor FBG dengan memodulasi intensitas cahaya laser dioda yang memiliki karakteristik quasi-monokromatis.

Pada penelitian ini, cahaya laser dioda $\lambda=1553,96 \mathrm{~nm}$ dirambatkan kedalam FBG $\lambda_{\text {Bragg }}=1554 \mathrm{~nm}$. Respon transmisi intensitas cahaya laser diukur menggunakan power meter, seperti setup percobaan yang ditunjukkan pada Gambar 2 . FBG diikatkan pada kantilever yang terbuat dari bahan plastik berbentuk tabung. Panjang dan diameter kantilever berturut-turut $6,46 \mathrm{~cm}$ dan $0,25 \mathrm{~cm}$. Pada ujung bebas lantilever diikatkan sebuah pelampung yang terbuat dari bahan stereoform. Selanjutnya, pelampung tersebut diapungkan dalam gelas kimia yang berisi air. Level ketinggian air dinaikan dan diturunkan setiap $0,1 \mathrm{~cm}$ kemudian diukur nilai intensitas laser dioda menggunakan power meter.
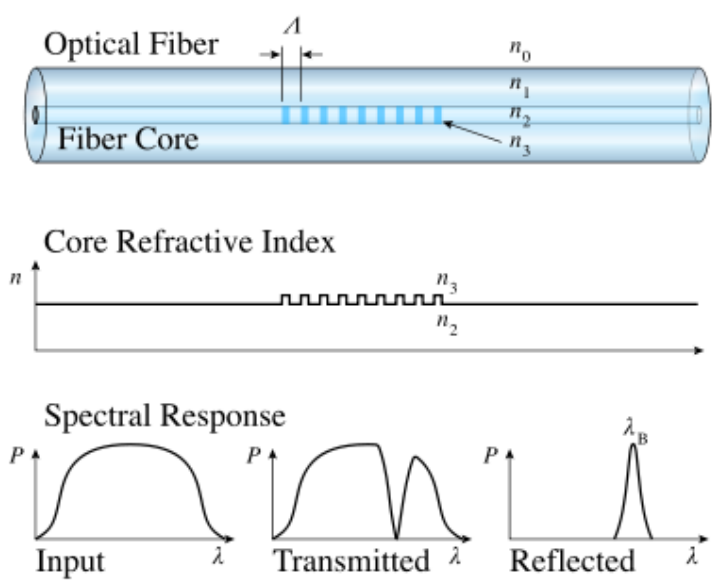

Gambar 1. Prinsip kerja FBG [6].

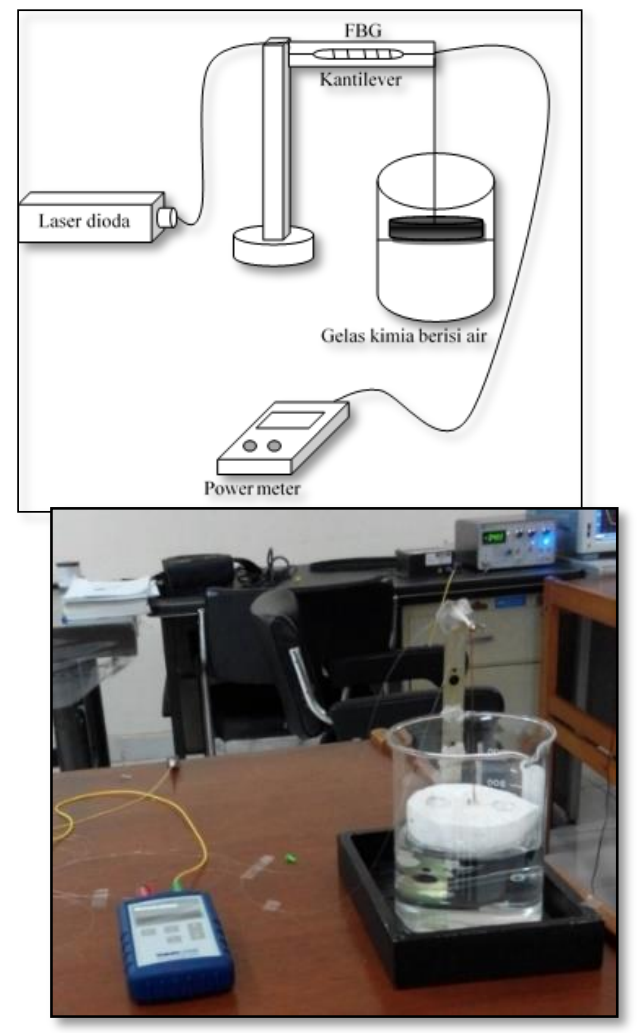

Gambar 2. Set-up percobaan pengukuran level air menggunakan FBG dengan modulasi intensitas cahaya laser dioda. 


\section{Hasil dan Pembahasan}

Prinsip modulasi intensitas laser pada sensor FBG adalah menggeser respon cahaya FBG terhadap cahaya laser dan memanfaatkan lebar bandwidth FBG. Oleh karena itu bandwidth laser dioda harus lebih kecil dari bandwidth respon cahaya FBG. Pada penelitian ini, laser dioda dan FBG memiliki lebar badwidth berturutturut $0,12 \mathrm{~nm}$ dan $0,36 \mathrm{~nm}$, seperti ditunjukkan pada Gambar 3.

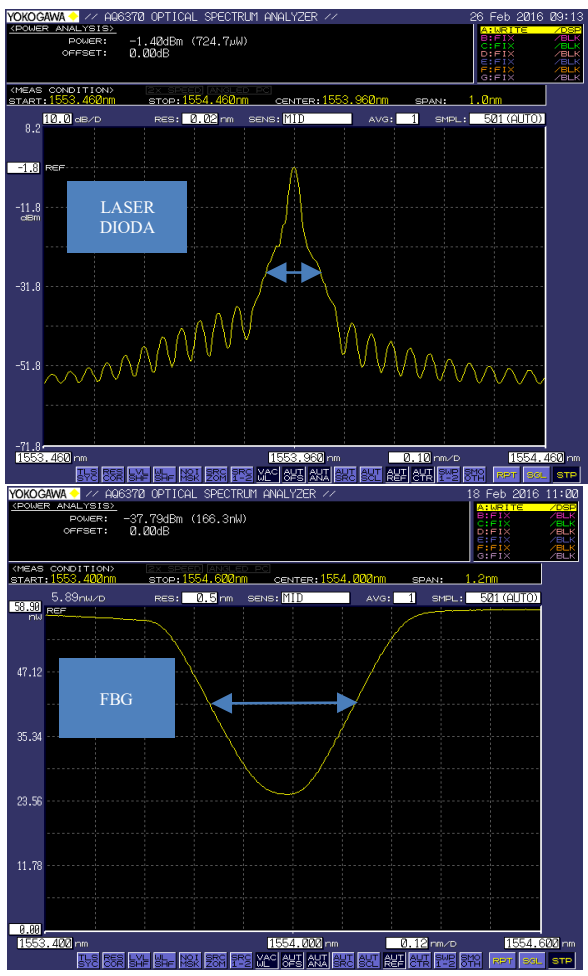

Gambar 3. Bandwidth laser dioda (atas) dan respon transmisi cahaya FBG (bawah).

Pengukuran level ketinggian air dilakukan dengan cara menggeser respon cahaya transmisi FBG. Respon cahaya transmisi FBG dapat bergeser karena terjadi peregangan pada kantilever akibat gerakan naik/turun pelampung. Pergeseran respon cahaya transmisi FBG ini kemudian mempengaruhi tingkat transmisifitas laser sehingga intensitas yang dideteksi mengalami perubahan. Hasil pengukuran intensitas laser terhadap kenaikan dan penurunan level air setiap $0,1 \mathrm{~cm}$ ditunjukkan pada Gambar 4. Rentang level ketinggian air ditentukan mulai dari $6,8 \mathrm{~cm}$ sampai $8,1 \mathrm{~cm}$. Berdasarkan grafik pada Gambar 4, perubahan intensitas cahaya laser memiliki hubungan yang linier dengan perubahan level ketinggian air. Linieritas menunjukkan bahwa sensor dapat menghasilkan intensitas yang berubah secara kontinu sebagai tanggapan terhadap tinggi permukaan air. Validitas pengulangan pengukuran dilakukan dengan cara melakukan percobaan sebanyak 3 kali, seperti ditunjukkan pada Gambar 5 dan Gambar 6. Baik kenaikan maupun penurunan level air memiliki tingkat validitas pengulangan yang baik. Standar deviasi dan standar error pada kenaikan level air masing-masing 0,05 dan 0,028. Sedangkan standar deviasi dan standar error pada penurunan level air masing-masing 0,08 dan 0,045. Selanjutnya, sensitivitas kenaikan dan penurunan level air terhadap intensitas laser dioda masing-masing sebesar $6,8949 \mathrm{dbm} / \mathrm{cm}$ dan 6,9309 $\mathrm{dbm} / \mathrm{cm}$. Sedangkan resolusi pengukuran sensor ini sebesar $0,1 \mathrm{~cm}$.

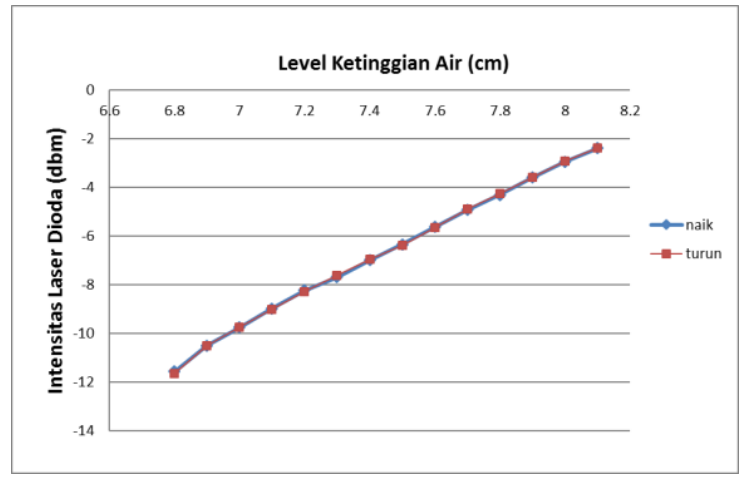

Gambar 4. Pengaruh kenaikan dan penurunan level ketinggian air terhadap intensitas laser dioda

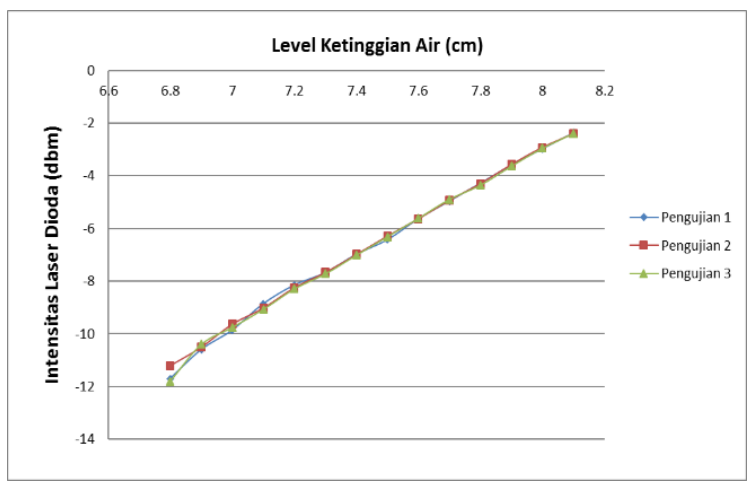

Gambar 5. Grafik hubungan kenaikan level ketinggian air terhadap intensitas selama 3 kali pengujian 


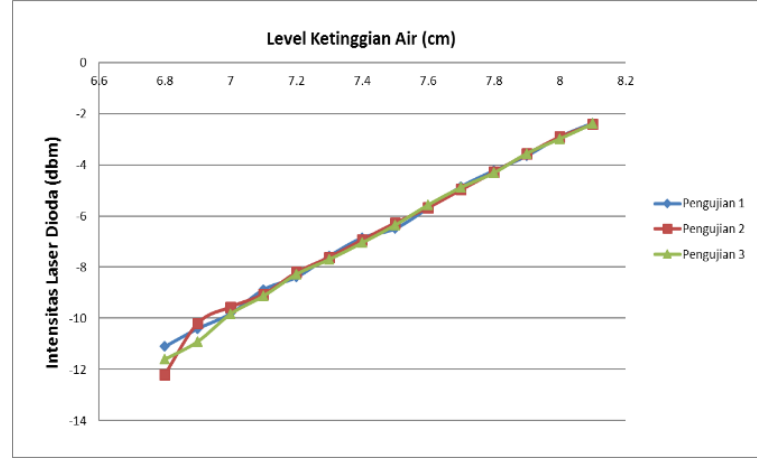

Gambar 6. Grafik hubungan penurunan level ketinggian air dengan intensitas laser dioda selama 3 kali pengujian

\section{Simpulan}

Metode modulasi intensitas cahaya laser dapat diterapkan untuk mengukur level ketinggian air. Hasil percobaan menunjukkan bahwa sensor memiliki kelinieran dan validitas pengukuran yang baik. Secara prinsip, metode ini dapat diterapkan untuk aplikasi yang lebih besar, seperti monitoring level air pada bendungan atau waduk.

\section{Ucapan Terimakasih}

Penulis mengucapkan terima kasih kepada Pusat Penelitian Fisika LIPI, khususnya laboratorium optoelektronika, yang telah memfasilitasi terlaksananya penelitian ini.

\section{Daftar Acuan}

[1] Lingtao Meng, Yunqi Liu1, Tingyun Wang, A Novel Liquid Level Monitoring Sensor System Using A Fiber Bragg Grating, ICSSC 2013, pp. 145-148.

[2] Antonio-Lopez, Jose E, May-Arrioja, Daniel A, Likamwa, Patrick, Fiber-optic liquid level sensor, IEEE Photonics Technology Letters, 2011, 23, (23), pp.1826-1828.

[3] Yun B., Chen N., and Cui Y., Highly sensitive liquidlevel sensor based on etched fiber Bragg grating, IEEE Photonics Technology Letters, 2007, 19, (21), pp. 1747-1749

[4] Dong X., Zhao R., Detection of liquid-level variation using a side-polished fiber Bragg grating, Optics \& Laser Technology, 2010, 42, (1), pp. 214-218

[5] Johannes Skaar and Knut Magne Risvik, A Genetic Algorithm for the Inverse Problem in Synthesis of Fiber Gratings, Journal of Lightwave Technology, vol. 16, No. 10, 1998, pp. 1928-1932.

[6] Wen Xiong, C. S. Cai, and Xuan Kong, Instrumentation design for bridge scour monitoring using fiber Bragg grating sensors, Applied Optics, vol. 51, No. 5, 2012, pp. 547557. 